\title{
Restoration of liver insulin signaling in Insr knockout mice fails to normalize hepatic insulin action
}

\author{
Haruka Okamoto, ${ }^{1,2}$ Silvana Obici, ${ }^{3}$ Domenico Accili, ${ }^{1}$ and Luciano Rossetti ${ }^{3}$ \\ ${ }^{1}$ Department of Medicine and 2Institute of Human Nutrition, College of Physicians and Surgeons, \\ Columbia University, New York, New York, USA. ${ }^{3}$ Departments of Medicine and Molecular Pharmacology and \\ Diabetes Research and Training Center, Albert Einstein College of Medicine, New York, New York, USA.
}

\begin{abstract}
Partial restoration of insulin receptor Insr expression in brain, liver, and pancreatic $\beta$ cells is sufficient for rescuing Insr knockout mice from neonatal death, preventing diabetes ketoacidosis, and normalizing life span and reproductive function. However, the transgenically rescued mice (referred to as L1) have marked hyperinsulinemia, and approximately $30 \%$ develop late-onset type 2 diabetes. Analyses of protein expression indicated that $\mathrm{L} 1$ mice had modestly reduced Insr content but normal insulin-stimulated Akt phosphorylation in the liver. Conversely, $\mathrm{L} 1 \mathrm{mice}$ had a near complete ablation of Insr protein product in the arcuate and paraventricular nuclei of the hypothalamus, which was associated with a failure to undergo insulin-dependent Akt phosphorylation in the hypothalamus. To test whether reconstitution of insulin signaling in the liver is sufficient for restoring in vivo hepatic insulin action, we performed euglycemic hyperinsulinemic clamp studies in conscious L1 and WT mice. During the clamp, L1 mice required an approximately $50 \%$ lower rate of glucose infusion than did WT controls, while the rate of glucose disappearance was not significantly altered. Conversely, the rate of glucose production was increased approximately 2 -fold in $\mathrm{L} 1$ mice. Thus, restoration of hepatic insulin signaling in Ins $r$ knockout mice fails to normalize the in vivo response to insulin.
\end{abstract}

\section{Introduction}

Type 2 diabetes is a complex metabolic disorder characterized by insulin resistance and impaired $\beta$ cell function (1). Patients with overt diabetes demonstrate insulin resistance in all major insulin target tissues (muscle, adipose, and liver). Insulin plays key roles in the regulation of glucose (1), lipid (1), and protein homeostasis $(2)$ as well as energy balance $(3,4)$. The primary site(s) of insulin resistance remains undetermined. However, it is difficult to determine whether the impairment in insulin action at a certain site is a primary defect or a consequence of chronic hyperinsulinemia, hyperlipidemia, and/or glucotoxicity (5). Thus, whether insulin resistance represents a generalized impairment of insulin action or is initially restricted to specific organs or tissues remains to be delineated. To examine the consequences of a primary defect in insulin signaling, we and others have generated several mouse models bearing targeted gene mutations that affect insulin receptor (Insr) expression and signaling (6). These studies have suggested that, in addition to the sites where glucose transport is insulin regulated (skeletal muscle, adipose cells, and heart), other insulin target tissues, such as liver (7), pancreatic $\beta$ cells (8), and brain (9), also play

\footnotetext{
Nonstandard abbreviations used: ARC, arcuate; FIRKO, fat insulin receptor knockout; Foxo1, forkhead box O1; GIR, glucose infusion rate; GP, glucose production; G6Pase, glucose-6-phosphatase; Insr, insulin receptor; IRS, insulin receptor substrate 1 ; LIRKO, liver insulin receptor knockout; MIRKO, muscle insulin receptor knockout; PEP, phosphoenolpyruvate; PRCF, percentage of relative cumulative frequency; PVN, paraventricular; $\mathrm{R}_{\mathrm{a}}$, rate of glucose appearance; $\mathrm{RQ}$, respiratory quotient; UDP-glucose, uridine-diphospho-glucose; $\mathrm{VO}_{2}$, resting oxygen consumption. Conflict of interest: The authors have declared that no conflict of interest exists.

crucial roles in the regulation of energy balance, in the pathogenesis of glucose intolerance and insulin resistance, and/or in the protection from $\beta$ cell failure (7-9). However, it is now well established that there are redundant mechanisms for interorgan communication among the various sites of insulin action (10-13) and that these complex interactions play a pivotal role in common forms of insulin resistance (13). In order to investigate these interactions, it is important to characterize the impact of selective defects in Insr functions not only in isolation but also in combination with each other $(14,15)$. In this regard, we have recently demonstrated that Insr knockout mice can be rescued from neonatal death and protected against the development of diabetes by the partial restoration of Insr expression in liver, pancreatic $\beta$ cells, and brain (16). Here we report that these mice, in addition to lacking Insr function in muscle and fat, also exhibit defective insulin signaling in the hypothalamus but display normal activation of insulin signaling in the liver. Thus, they represent an excellent model for discerning the effect of liver insulin signaling in the context of defective insulin signaling in extrahepatic sites. We used euglycemic hyperinsulinemic clamps in conscious mice to show that the mutant mice are markedly resistant to insulin action on hepatic gluconeogenesis and glucose production (GP).

\section{Results}

General characteristics of the experimental animals. To investigate the contribution of Insr signaling in extrahepatic tissues to the control of hepatic glucose fluxes, we studied a genetic model of insulin resistance (L1 mice) in which transgenic Insr expression was driven by the transthyretin promoter in Insr knockout mice. L1 mice lack endogenous Insr but express transgene-encoded 
Table 1

General characteristics of the experimental groups

$\begin{array}{lccc}\text { Groups } & \text { WT } & \text { L1 } & \text { P values } \\ \text { Body weight }(\mathrm{g}) & 29.2 \pm 1.2 & 28.3 \pm 1.1 & 0.61 \\ \text { Fat-free mass }(\mathrm{g})^{\mathrm{A}} & 26.6 \pm 0.8 & 28.4 \pm 1.2 & 0.25 \\ \text { Fat mass }(\mathrm{g})^{\mathrm{A}} & 4.2 \pm 0.9 & 2.3 \pm 0.4 & 0.09 \\ \text { Glucose }(\mathrm{mM}) \text {; basal } & 8.3 \pm 0.3 & 7.8 \pm 0.5 & 0.26 \\ \text { FFA }(\mathrm{mM}) & 1.5 \pm 0.2 & 1.3 \pm 0.2 & 0.59 \\ \text { Glycerol }(\mu \mathrm{g} / \mathrm{dl}) & 10.7 \pm 2.3 & 10.4 \pm 1.2 & 0.63 \\ \text { Insulin }(\mathrm{ng} / \mathrm{ml}) & 1.2 \pm 0.5 & 8.2 \pm 1.3 & <0.01 \\ \text { Glucagon }(\mathrm{pM}) & 49 \pm 12 & 48 \pm 7 & 0.56 \\ \text { Adiponectin }(\mu \mathrm{g} / \mathrm{ml}) & 4.7 \pm 0.7 & 13.9 \pm 1.5 & <0.01 \\ \text { Leptin }(\mathrm{ng} / \mathrm{ml}) & 0.9 \pm 0.2 & 1.8 \pm 0.3 & 0.09 \\ \text { Resistin }(\mathrm{ng} / \mathrm{ml}) & 33 \pm 6 & 42 \pm 9 & 0.38 \\ \text { GP }(\mathrm{mg} / \mathrm{kg} / \mathrm{min}) & 29 \pm 3 & 27 \pm 4 & 0.78 \\ \end{array}$

Body weight, body composition, plasma substrate and hormone levels, and basal rate of GP following fast of approximately 5 hours (in the absence of insulin treatment). Basal, absence of insulin infusion. ${ }^{A}$ Results from 8 WT and $7 L 1$ mice. $P$ values indicate $L 1$ versus WT mice.

Insr mainly in liver and, to a lesser extent, in pancreatic $\beta$ cells and in various brain regions (16). The majority ( $70 \%)$ of $\mathrm{L} 1 \mathrm{mice}$ are able to maintain normal glucose levels, but their circulating insulin levels are increased compared with those in WT. Approximately $30 \%$ of the remaining L1 mice develop diabetes mellitus, with average onset at 8 months of age. L1 mice have normal life spans, reproductive function, and pancreatic islet morphology and morphometry (16). For the present experiments, we compared 12 3-month-old normoglycemic L1 mice and 9 WT male mice. There were no differences in the mean body weights between the 2 groups (Table 1). Since tissue-selective ablation of Insr in either fat (17) or muscle (18) alter body composition, we also determined the impact of the combined ablation of Insr in these insulin-target tissues on fat mass and fat-free mass in a subgroup of L1 and WT mice. Overall, the contribution of fat mass to body weight was moderately decreased ( $47 \%)$ in L1 compared with WT mice, but this difference did not achieve statistical significance (Table 1). Fasting plasma glucose, FFA, glycerol, glucagon, resistin (Table 1), and triglyceride (not shown) levels were also similar in L1 and WT mice. However, plasma insulin and adiponectin levels were significantly increased in L1 compared with WT mice (Table 1). Despite a tendency toward lower fat mass, L1 mice also displayed moderately higher levels of another adipose-derived hormone, leptin. Finally, the rate of GP was similar in the 2 groups of mice (Table 1 ).

L1 mice display impaired insulin signaling in bypothalamus but not in liver. Representative Western blot analyses and quantification of the levels of insulin-signaling proteins in liver and hypothalami of L1 and WT mice are displayed in Figure 1. Expression of Insr through the transgene restored the levels of Insr protein in liver of L1 mice to approximately $60 \%$ of the levels observed in WT animals. To determine whether downstream insulin signaling was altered in the liver of L1 mice, we next examined the effect of insulin on the phosphorylation of insulin receptor substrate 1 (IRS1), Akt, and forkhead box O1 (Foxo1) and on the association of P85 with IRS1 following i.p. injection of insulin or saline. Upon insulin stimulation, both L1 and WT mice showed a robust increase in phosphorylated Akt protein levels without changes in total Akt protein concentrations (Figure 1A). Similarly, IRS1 and Foxo1 phosphorylation and the IRS1 association with P85 were similar in the 2 groups (Figure 1B). Western blots were also performed on liver samples obtained at the completion of the insulin clamp studies. The phosphorylation of Akt in these samples was also similar in L1 and WT mice (data not shown). Taken together, these results suggest that hepatic insulin signaling is not diminished in L1 mice.

We next examined insulin signaling in the hypothalamus. Expression of Insr through the transgene restored Insr protein levels in the hypothalamus of L1 mice to approximately $30 \%$ of the levels observed in WT animals (Figure 1C). To determine whether hypothalamic insulin signaling was altered in L1 mice, we next examined the effect of insulin on Akt phosphorylation. To this end, we isolated hypothalami from L1 and WT mice 30 minutes after i.p. insulin or saline injections. In saline-injected L1 and WT mice, total and phosphorylated Akt levels were similar. However, insulin increased the phosphorylation of hypothalamic Akt in WT mice but failed to do so in L1 mice (Figure 1C). These data indicate that $\mathrm{L} 1$ mice are resistant to activation of insulin signaling in the hypothalamus. In addition, we microdissected arcuate (ARC) and paraventricular (PVN) nucleus regions of the hypothalamus to determine Insr protein levels. L1 mice exhibited a near-complete ablation of Insr (protein levels $\leq 10 \%$ of WT) in the ARC and PVN regions, both of which play crucial roles in the control of autonomic function, intermediary metabolism, and whole-body energy homeostasis.

L1 mice have decreased whole-body oxygen consumption. Insulin plays a pivotal role in the regulation of lipid biosynthesis and oxidation. Lack of skeletal muscle and adipose tissue insulin signaling may induce changes in whole-body energy expenditure and substrate oxidation (6). To this end, we measured respiratory exchanges by indirect calorimetry in L1 and WT mice. Despite having similar body weight, L1 and WT mice tend to differ in their body composition, with L1 mice displaying modest decreases in fat mass and increases in fat-free mass (Table 1 and Figure 2A). Age- and weight-matched male mice were placed in individual metabolic cages, and their food intake, activity, and gas exchange data were recorded for 2-3 consecutive days. Daily food intake was similar in both groups (Figure 2B). L1 mice displayed a significant increase in resting oxygen consumption $\left(\mathrm{VO}_{2}\right)$ by $14 \%(3015 \pm 87 \mathrm{ml} / \mathrm{kg} / \mathrm{h}$ vs. $2574 \pm 132 \mathrm{ml} / \mathrm{kg} / \mathrm{h}$ in WT $)$ and total $\mathrm{VO}_{2}$ by $13 \%(3954 \pm 131 \mathrm{Kcal} / \mathrm{h}$ vs. $3437 \pm 116 \mathrm{Kcal} / \mathrm{h}$ in WT) compared with that shown in WT mice (Figure 2C). The fasting respiratory quotient (RQ) was also lower in $\mathrm{L} 1$ mice compared with the WT control group $(0.75 \pm 0.01$ versus $0.80 \pm 0.01$, respectively) (Figure $2 \mathrm{D}$ ). To evaluate differences in RQ throughout the daily fasting and feeding cycles, RQ measurements were expressed as percentages of relative cumulative frequency (PRCFs) (19). This type of analysis complements the simple average of RQ values and is designed to detect physiologically relevant changes in the daily fluctuations of substrate oxidation. The PRCF curve for L1 mice shows a leftward shift as compared to that for WT, which indicates a higher frequency of lower RQ in L1 mice throughout the fasting/feeding cycle (Figure 2E). This lower RQ may reflect the upregulation of genes involved in fatty acid oxidation. Alternatively, the lack of insulin signaling may diminish net lipid biosynthesis, which would also result in a lower RQ. These changes in $\mathrm{RQ}, \mathrm{VO}_{2}$, and energy expenditure were not accounted for by differences in physical activity during the gas exchange measurements (Figure 2F). 
A

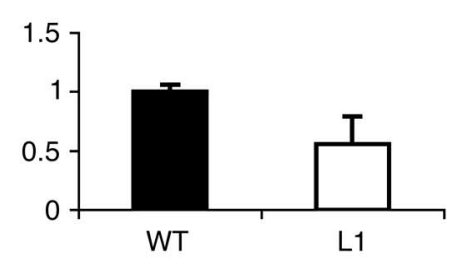

Insr

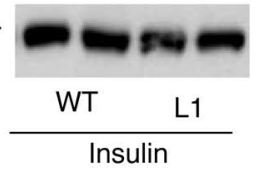

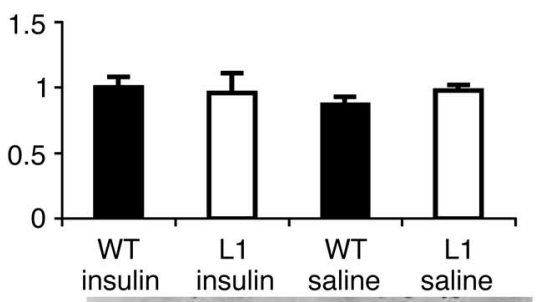

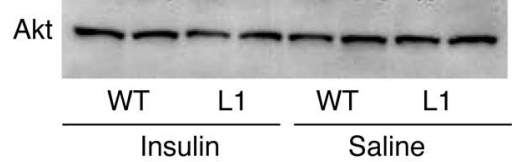

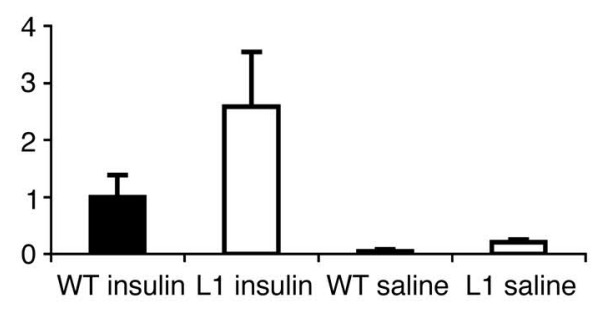

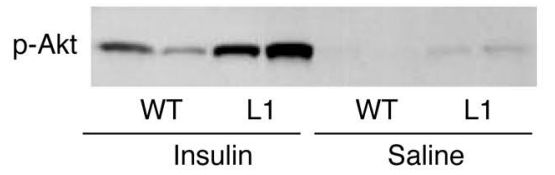

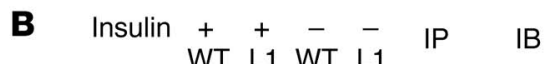
1. WT L1 WT LI IRS1 pY
2. $\infty=$ IRS1 IRS1
3. $=--m$ IRS1 p85
4. $\longrightarrow$ -

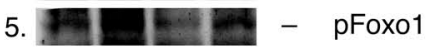
6. - - - Foxo1

C Hypothalamus
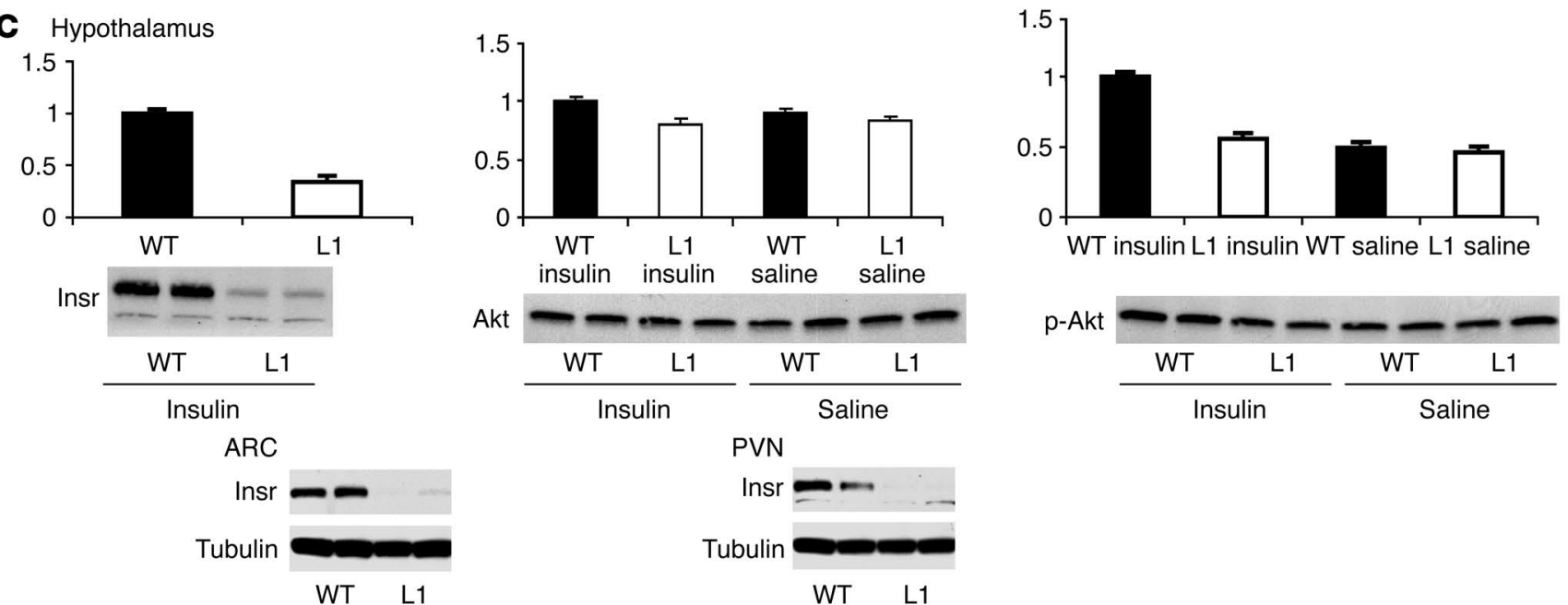

Figure 1

Activation of insulin signaling. (A) We performed immunoblot analysis to measure Insr, Akt, and phosphorylated Akt (Ser473) levels (left, middle, and right panels, respectively) in liver extracts from WT (black bars) and L1 (white bars) mice 10 minutes after i.p. injections of insulin ( $0.5 \mathrm{U} / \mathrm{kg}$ body weight) or saline. Representative blots are shown. The bar graphs represent mean \pm SEM of arbitrary densitometric units from 3 independent experiments. (B) We immunoprecipitated equal amounts ( $3 \mathrm{mg}$ protein) of liver extracts using anti-IRS1 antibodies and immunoblotted the precipitants using antiphosphotyrosine (pY) antibodies (panel 1) or anti-PI3K p85 antibodies (panel 3). After stripping antibodies from the filter, we immunoblotted it using anti-IRS1 antibodies (panel 2). We immunoblotted equal amounts (100 $\mu \mathrm{g}$ protein) of total liver extracts using p85 antibodies (panel 4), phosphorylated Foxo1 antibodies (panel 5), or Foxo1 antibodies (panel 6). (C) We performed immunoblot to measure Insr (top left panel), Akt (top middle panel), and phosphorylated Akt (Ser473) levels (top right panel) in hypothalamic extracts derived from WT and L1 mice thirty minutes after an i.p. injection of insulin ( $0.5 \mathrm{U} / \mathrm{kg}$ body weight) or saline. We performed immunoblot for Insr and $\beta$-tubulin in ARC (bottom left) and PVN (bottom right) region extracts derived from WT and L1 mice. Representative blots are shown.

L1 mice display in vivo insulin resistance during insulin clamp studies. To assess the metabolic effects of insulin in vivo, a similar increase in the plasma insulin concentrations $(\sim 9 \mathrm{ng} / \mathrm{ml})$ was generated. The plasma glucose concentrations were maintained at approximately $8 \mathrm{mM}$ by a variable glucose infusion. Thus, conscious mice with similar increases in the steady-state levels of insulin and similar glucose levels were compared. During the clamp studies, the circulating levels of glucose, FFA, glycerol, and glucagon and the increments in plasma insulin levels were similar in L1 and WT mice (Table 2). As observed in fasted mice, the plasma adiponectin levels were significantly higher in L1 compared with WT mice (Table 2). We achieved steady-state conditions for plasma glucose-specific activity within 40 minutes of the beginning of the clamp period. The effects of a similar increase in cir- 

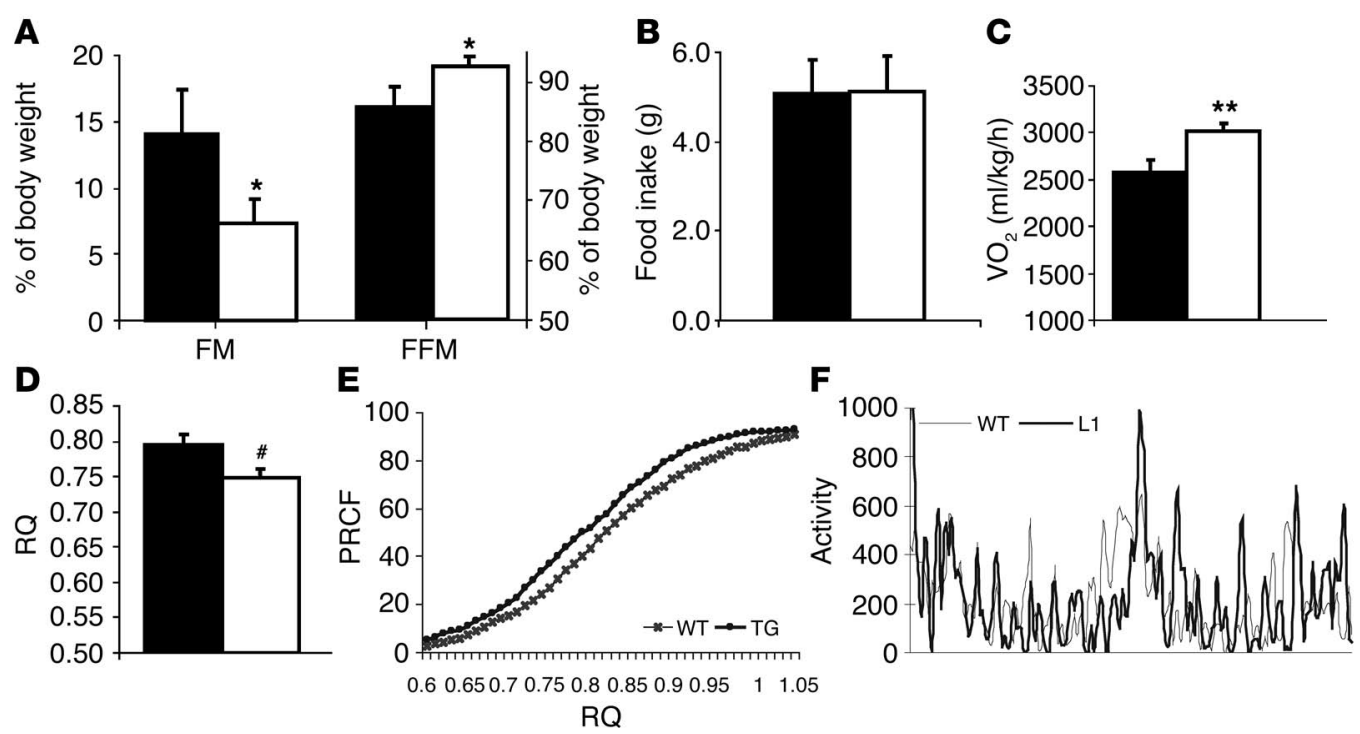

Figure 2

Impact of Insr genotype on energy balance. (A) Body composition of 2- to 3-month-old L1 (white bars) and WT (black bars) mice ( $n=5$ each). Fat mass is significantly decreased and free-fat mass is increased in L1 versus WT mice. ${ }^{*} P=0.05$. (B) Daily food intake was similar in both groups. (C) $\mathrm{VO}_{2}$ in L1 mice was significantly increased compared with that in WT mice. ${ }^{*} P=0.016$. (D) Twenty-four-hour average resting RQ was significantly decreased in L1 mice versus WT mice. ${ }^{P}=0.03$. (E) PRCF from 24-hour calorimetry measurements. L1 mice (filled circles) display a consistent shift of RQ toward lower values compared to WT mice (crosses). Each curve is derived from 770 measurements of RQ from L1 and WT mice ( $n=9$ mice per group). (F) Activity measured as horizontal movement recorded over 24-hour period in L1 (thick line) and WT (thin line) mice. The values represent mean \pm SEM.

culating insulin concentrations on the rate of glucose infusion (GIR) as well as the rates of tissue glucose uptake and muscle glucose transport are displayed in Figure 3. All measurements were performed during the final 50 minutes of the clamp. The GIR required in order to maintain target glucose concentration during the hyperinsulinemic clamp study was decreased by $50 \%$ in L1 mice, suggestive of insulin resistance $(20.9 \pm 3.1$ and $41.8 \pm 6.2 \mathrm{mg} / \mathrm{kg}$ per minute in L1 and WT, respectively; $P=0.014$; Figure 3B). However, the rate of whole-body glucose disappearance $\left(\mathrm{R}_{\mathrm{d}}\right)$ was similar in the 2 groups $(47.9 \pm 2.4$ and $53.9 \pm 3.9 \mathrm{mg} / \mathrm{kg}$ per minute in L1 and WT, respectively; $P=0.27$; Figure 3C). Insulin-stimulated glucose transport activity was also estimated by monitoring the rate of whole-body clearance of 2-deoxyglucose $\left(\mathrm{R}_{\mathrm{g}}\right)$ and its rate of phosphorylation in muscle during the last 45 minutes of the insulin clamp studies. Since 2-deoxyglucose is transported and phosphorylated but is not further metabolized, determination of the tissue content of 2-deoxyglucose-6-phosphate can be used to produce a valid estimate of the rate of glucose transport and phosphorylation in individual tissues. Insulin-stimulated glucose transport activity was only modestly decreased in L1 mice compared with WT littermates (by $16 \%$ of WT), but this decrease did not achieve statistical significance (Figure 3D). Thus, there appear to be alternative signaling pathway(s) for insulin-stimulated glucose transport and uptake in muscle; changes in the rate of glucose uptake did not account for the insulin resistance in $\mathrm{L} 1$ mice.

L1 mice display severe bepatic insulin resistance during insulin clamp studies. To elucidate the mechanism responsible for the marked reduction in THE GIR in L1 mice, we examined the rates of endogenous GP, the in vivo flux through glucose-6-phosphatase (G6Pase), and the relative contributions of gluconeogenesis, gly- cogenolysis, and glucose cycling to in vivo G6Pase flux (Table 3). During the insulin clamp studies, GP was approximately 2-fold greater (Figure 4A) in L1 mice than in WT controls $(27.0 \pm 3.1$ and $13.1 \pm 1.7 \mathrm{mg} / \mathrm{kg}$ per minute in $\mathrm{L} 1$ and $\mathrm{WT}$, respectively; $P=0.0007)$. Since the basal rates of GP were similar (Table 1 ), these data suggest that a physiological elevation in circulating insulin levels failed to suppress GP in L1 mice and that this defect in hepatic insulin action largely accounts for the marked reduction in the GIR during the insulin clamp studies. As shown in Figure 4A, the flux through G6Pase was markedly increased in L1 mice in parallel with the elevation in GP $(P<0.0001)$. The increase in GP was largely accounted for by a marked stimulation of gluconeogenesis $(P=0.0004)$, while glycogenolysis $(P=0.142)$ was only modestly increased $(P=0.143$; Figure $4 \mathrm{~B})$. Consistent with the marked changes in glucose output, rates of glucose cycling were also increased in L1 mice $(P=0.056$; Figure $4 \mathrm{C})$. Based

\section{Table 2}

Blood chemistries during the insulin clamp studies

\begin{tabular}{lccc} 
Groups & WT & L1 & $P$ values \\
Glucose $(\mathrm{mM})$ & $8.1 \pm 0.2$ & $8.1 \pm 0.3$ & 0.46 \\
FFA $(\mathrm{mM})$ & $0.7 \pm 0.1$ & $0.7 \pm 0.2$ & 0.69 \\
Glycerol $(\mu \mathrm{g} / \mathrm{dl})$ & $5.9 \pm 0.4$ & $5.3 \pm 0.5$ & 0.93 \\
Insulin $(\mathrm{ng} / \mathrm{ml})$ & $10.3 \pm 1.2$ & $19.5 \pm 3.9$ & 0.15 \\
$\Delta$ Insulin $(\mathrm{ng} / \mathrm{ml})$ & $9.0 \pm 0.9$ & $9.8 \pm 2.4$ & 0.82 \\
Adiponectin $(\mu \mathrm{g} / \mathrm{ml})$ & $2.3 \pm 0.6$ & $5.6 \pm 0.8$ & $<0.01$ \\
Glucagon $(\mathrm{pM})$ & $45 \pm 6$ & $48 \pm 5$ & 0.56 \\
\hline
\end{tabular}

Plasma substrate and hormone levels at the end of the insulin clamp period are shown. $P$ values indicate L1 versus WT mice. 
A

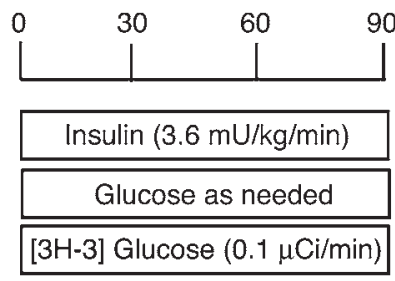

B

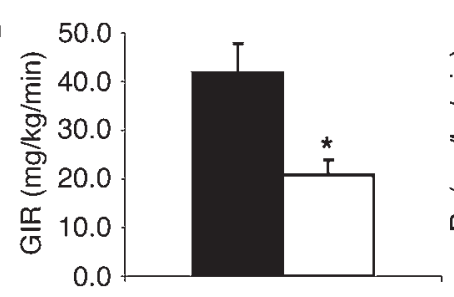

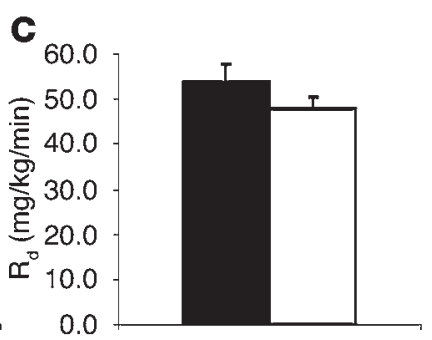

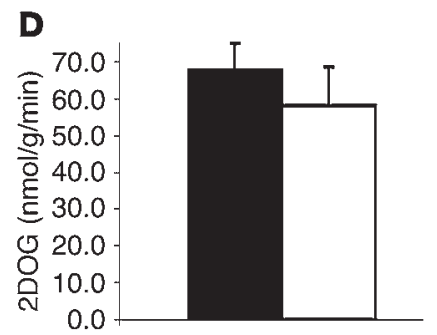

Figure 3

Impact of Insr genotype on in vivo insulin action. (A) Scheme of the euglycemic insulin clamp studies performed in conscious mice. (B) The GIR was markedly decreased in L1 (white bars) compared with WT (black bars) mice. (C) The rate of whole-body glucose disappearance $\left(R_{d}\right)$ and $(\mathbf{D})$ the rate of muscle glucose transport (2DOG) were not significantly decreased in L1 compared with WT mice. Insulin clamp studies were performed in $11 \mathrm{~L} 1$ and 9 WT male animals. The values represent mean \pm SEM.

on the above results, we examined whether $\mathrm{L} 1$ mice displayed increased hepatic expression of insulin-regulated gluconeogenic transcripts at the completion of the infusions (Figure 4D). Realtime PCR analyses revealed no changes in liver G6Pase and phosphoenolpyruvate carboxykinase (PEPCK) or Igfbp 1 mRNA levels. Thus, the marked increases in the in vivo flux through G6Pase and phosphoenolpyruvate-gluconeogenesis (PEP-gluconeogenesis) in L1 mice are not due to increased hepatic expression of the catalytic subunit of G6Pase and PEPCK. These findings are consistent with the preserved action of insulin to stimulate hepatic Akt and Foxo1 phosphorylation (Figure 1).

\section{Discussion}

Fasting hyperglycemia is the hallmark of diabetes mellitus, and increased GP is a major determinant of fasting hyperglycemia in diabetes mellitus (20). It is now well established that the shortterm effects of insulin on hepatic glucose fluxes involve both direct effects on the liver (21) and indirect effects mediated via extrahepatic actions of insulin (22-24). We have recently provided evidence that indirect effects of insulin on GP also include the activation of hypothalamic insulin signaling (25). Thus, shortterm effects of insulin on hepatic glucose fluxes may be divided into 3 major components: (a) direct effects on the liver (21) (mostly leading to rapid inhibition of glycogenolysis); (b) indirect effects mediated via peripheral actions of insulin (22-24) (mostly on lipolysis); and (c) indirect effects mediated via activation of hypothalamic insulin signaling (25). Furthermore, insulin exerts potent long-term effects on liver gene expression and function (26). These more chronic actions of insulin can in turn markedly affect the acute responses to an increase in circulating insulin levels $(7,27)$.

The relative contributions of various organs to whole-body insulin action have been dramatically redefined through the use of novel genetic methods to introduce conditional null alleles in genes important for insulin signaling (13). Here, we report the metabolic characterization of mice with ablation of Insr in all tissues but the liver, pancreas, and brain (L1 mice). As recently reported, these mice display hyperinsulinemia, but diabetes mellitus does not develop in the majority of their offspring (16). In these mice, expression of Insr protein in the liver was restored to approximately $60 \%$ of normal. Most importantly, this level of protein expression was sufficient to restore insulin's ability to stimulate downstream liver signaling (Figure 1, A and B). The normalization of insulin signaling in L1 mice is also manifested in the lack of effects on the expression of several insulin-regulated proteins such as G6Pase, Pepck, and Igfbp1 (Figure 4D). Conversely, Insr protein was only restored to approximately $30 \%$ of normal levels in the whole hypothalamus and to $10 \%$ or less of normal levels in the ARC and PVN nuclei of L1 mice (Figure 1C). Furthermore, the ability of insulin to stimulate the hypothalamic phosphorylation of Akt was markedly impaired. Finally, Insr protein was not detected in other canonical sites of insulin action, such as skeletal muscle and adipose tissue. Thus, this animal model allowed us to refine our understanding of the relative roles of hepatic and extrahepatic insulin signaling in the regulation of glucose fluxes in the liver.

Insulin signaling in liver. A major finding of this study is that severe hepatic insulin resistance is a prominent feature of L1 mice. A primary decrease in Insr signaling due to reduced Insr protein levels in liver could account for hepatic insulin resistance via impairment of the direct actions of insulin on the liver. Consistent with this postulate, hepatocyte-specific and constitutive Insr ablation, as occurs in liver insulin receptor knockout

\section{Table 3}

Direct and indirect pathways of hepatic UDP glucose formation in WT and L1 mice.

\begin{tabular}{|c|c|c|c|}
\hline Group & WT & L1 & $P$ value \\
\hline $\begin{array}{l}{\left[{ }^{3} \mathrm{H}\right] \text {-UDP-glucose }} \\
\text { Liver SA }(\mathrm{dpm} / \mathrm{nmol})\end{array}$ & $1.7 \pm 0.5$ & $2.3 \pm 0.5$ & 0.49 \\
\hline $\begin{array}{c}{\left[{ }^{3} \mathrm{H}\right] \text {-glucose plasma }} \\
\text { SA (dpm/nmol) }\end{array}$ & $25.8 \pm 1.9$ & $27.1 \pm 2.7$ & 0.44 \\
\hline$\%$ Direct & $7.9 \pm 2.7$ & $8.0 \pm 1.6$ & 0.99 \\
\hline $\begin{array}{l}{\left[{ }^{14} \mathrm{C}\right]-\text { UDP-glucose }} \\
\text { Liver SA (dpm/nmol) }\end{array}$ & $7.9 \pm 2.0$ & $18.6 \pm 1.6^{A}$ & 0.005 \\
\hline $\begin{array}{l}{\left[{ }^{14} \mathrm{C}\right]-\mathrm{PEP}} \\
\quad \text { Liver SA }(\mathrm{dpm} / \mathrm{nmol})\end{array}$ & $20.0 \pm 3.3$ & $22.8 \pm 5.8$ & 0.69 \\
\hline$\%$ Indirect & $20.2 \pm 2.5$ & $40.4 \pm 7.4^{\mathrm{A}}$ & 0.032 \\
\hline
\end{tabular}

Specific activities of plasma glucose, hepatic UDP-glucose, and PEP were used to calculate the contribution of plasma glucose and PEP-gluconeogenesis to the hepatic UDP-glucose pool following $\left[3^{-}{ }^{3} \mathrm{H}\right]$-glucose and $\left[\mathrm{U}-{ }^{14} \mathrm{C}\right]$-lactate infusions in rats at the completion of pancreatic/insulin clamp studies. SA, specific activity; \% direct, percentage of the hepatic UDP-glucose pool derived from plasma glucose calculated as the ratio of the specific activities of liver $\left[{ }^{3} \mathrm{H}\right]-$-UDP-glucose and plasma $\left[{ }^{3} \mathrm{H}\right]$-glucose; $\%$ indirect, percentage of the hepatic UDP-glucose pool derived from PEP-gluconeogenesis, calculated as the ratio of the specific activities of $\left[{ }^{14} \mathrm{C}\right]$-UDP-glucose to $2 \times\left[{ }^{14} \mathrm{C}\right]$-PEP. ${ }^{*} P<0.05 \mathrm{~L} 1$ versus WT. 
A
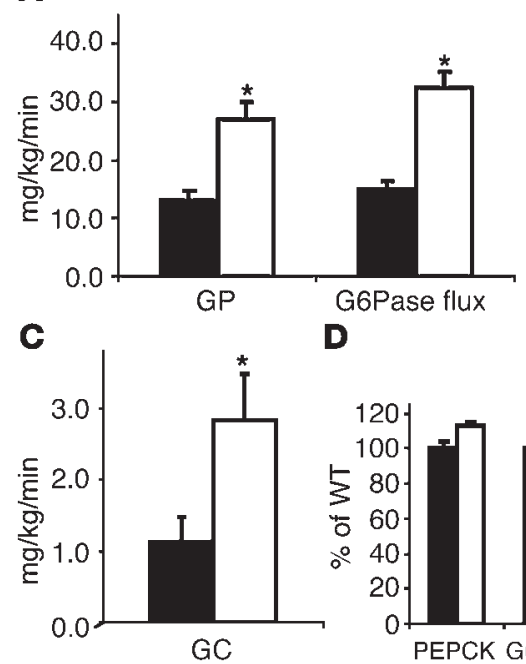

B

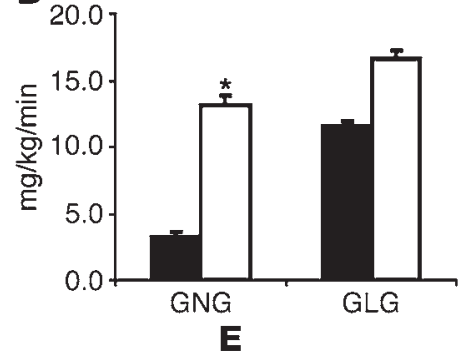

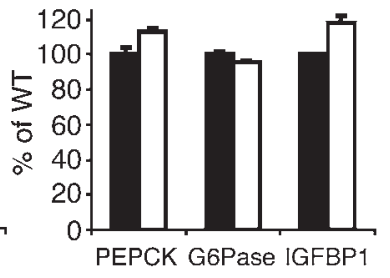

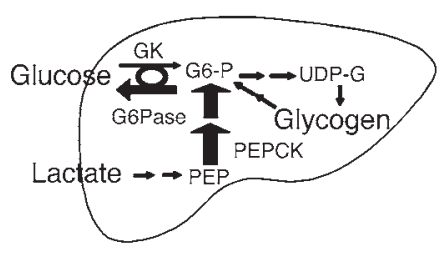

\section{Figure 4}

Impact of Insr genotype on hepatic glucose fluxes and gene expression. (A) The rates of endogenous GP and of G6Pase flux were markedly increased in L1 (white bars) compared with WT (black bars) mice. (B) The rate of gluconeogenesis (GNG) was markedly increased in L1 compared with WT mice, while the rate of glycogenolysis (GLG) was not significantly changed. (C) The rate of glucose cycling (GC) was also markedly increased in L1 compared with WT mice. (D) The hepatic expressions of insulin-responsive genes such as PEPCK, G6Pase, and IGFBP1 were not affected in L1 mice. (E) In summary, in the presence of physiological hyperinsulinemia, L1 mice displayed a dramatic increase in the rate of gluconeogenesis (indicated by the thicker arrows) that largely accounts for the increase in glucose output. GK, glucokinase; G6-P, glucose-6phosphate; UDP-G, UDP-glucose. The values represent mean \pm SEM.
(LIRKO) mice, result in marked increases in the expression of liver gluconeogenic enzymes, therefore validating the fundamental role of direct effects of insulin in the regulation of hepatic gene expression. Importantly, LIRKO mice also display progressive deterioration of liver function (7) and severe hepatic insulin resistance (27). However, in the present study, insulin administration resulted in similar IRS1, Akt, and Foxo1 phosphorylation in livers of L1 and WT mice. In this regard, insulin-stimulated PI3K activation, which leads to Akt and Foxo1 phosphorylation, has been shown to be essential for insulin suppression of hepatic gluconeogenesis (28). In keeping with this observation, the association of the P85 subunit of PI3K with IRS1 and the expression of key gluconeogenic enzymes were also preserved in L1 mice. Thus, the chronic action of insulin on hepatic gene transcription was largely normalized by transgenic expression of Insr in hepatocytes. Despite normalization of hepatic insulin signaling, the in vivo action of insulin on GP was markedly impaired in L1 mice. Moreover, it should be noted that the rate of glycogenolysis was not increased in L1 mice, consistent with intact hepatic (direct) insulin action on glycogenolysis (21). However, L1 mice displayed a 4-fold increase in the rate of gluconeogenesis, which accounted for most of the increase in GP. Taken together, these data indicate that liver insulin signaling is required for the chronic effects of insulin in the liver, but it is not sufficient to restore acute insulin action on gluconeogenesis and on GP in vivo. Thus, deficient insulin signaling at extrahepatic sites is responsible for hepatic insulin resistance in $\mathrm{L} 1$ mice. The presence of a chronic elevation in circulating insulin levels in the L1 mice may also exacerbate the defects in insulin action via secondary downregulation of insulin signaling.

Insulin signaling in bypothalamus. A primary decrease in Insr signaling in the hypothalamus could also account for hepatic insulin resistance via impairment of this indirect action of insulin on the liver. Over the last several years, multiple roles of insulin action in the brain have emerged. Inactivation of Insr in nestin-positive neurons results in obesity, hyperinsulinemia, and decreased female fertility (9). In Caenorhabditis elegans, the damer phenotype caused by mutations in the Insr ortholog daf-2 can be rescued by selective reexpression of daf-2 in the brain (29). Indeed, neural and reproductive inputs have been shown to control lifespan of C. elegans (30). Importantly, a reduction of approximately $50 \%$ in Insr protein levels in the mediobasal hypothalamus was sufficient to impair the ability of circulating insulin to inhibit $\operatorname{GP}(25,31)$ in rats. In the present study, hypothalamic Insr expression was blunted in the ARC and PVN nuclei and markedly decreased in the whole hypothalamus of L1 mice ( $-30 \%$ of WT levels), and insulin administration resulted in rapid Akt phosphorylation in the hypothalamus of WT, but not of L1, mice. Since stimulation of PI3K activity in the hypothalamus is required for insulin's inhibition of GP (31), the marked impairment in hypothalamic insulin signaling could be responsible for increased GP in L1 mice. The almost complete lack of Insr expression in the 2 hypothalamic nuclei examined suggests that the transgenic expression of these receptors within the hypothalamus is uneven and perhaps confined to specific cell types. The expression of Insr in selective regions of the hypothalamus may also account for some other facets of the phenotype of L1 mice, such as their restored fertility and the lack of lipodystrophy in this transgenic line compared with other lines (L2 and L3) of rescued mice (16).

Insulin signaling in muscle and fat. A surprising finding of our study is that the absence of insulin signaling in peripheral tissues, such as adipose tissues and muscle, did not significantly alter the rate of glucose disappearance and only modestly decreased the rate of muscle glucose transport in vivo. This suggests that insulin can promote glucose transport in peripheral tissues via alternative signaling pathways (13). Selective impairment in skeletal muscle and/or adipose cell insulin signaling has previously been investigated using diverse genetic approaches (32). Overall, deletion of muscle Insr, as occurs in muscle insulin receptor knockout (MIRKO) mice, failed to induce diabetes or glucose intolerance and induced only moderate insulin resistance (33) while adipose-selective Insr deletion, as occurs in fat insulin receptor knockout (FIRKO) mice, improved glucose tolerance and insulin sensitivity (17). The associated effects of the tissue-specific deletion of Insr on energy balance further complicates the inter- 
pretation of these experiments. In fact, MIRKO mice displayed obesity while FIRKO mice were lean and resistant to diet-induced obesity. In the present study, the absence of Insr in both muscle and adipose tissue led to a modest decrease in insulin action on tissue glucose uptake, apparently resulting in a metabolic phenotype that is intermediate between those reported in MIRKO and FIRKO mice. Once again, however, the lack of insulin signaling led to changes in energy metabolism, with the L1 mice displaying a tendency to be leaner than WT mice. L1 mice also feature increases in circulating adiponectin and resting energy expenditure and a decrease in RQ, probably reflecting preferential oxidation of lipid over carbohydrates. It is certainly possible that the moderate decrease in fat mass and/or the increased levels of adiponectin can account for the differences in the estimates of muscle glucose transport between L1 and the obese MIRKO mice, enhancing insulin resistance in the latter and with leanness partly offsetting the lack of insulin signaling in the former model. Regardless, it is quite clear that insulin signaling in skeletal muscle and in adipose tissue plays an important role in lipid storage and oxidation and in overall energy balance. A striking common finding in various animal models with absent or severely defective insulin signaling in skeletal muscle is that insulin can still promote glucose transport and phosphorylation. It is likely that signaling via type 1 IGF receptors accounts at least in part for these paradoxical findings (34).

Mice with Insr deletion develop diabetic ketoacidosis shortly after birth and die within the first week of life $(35,36)$. Among the pleiotropic functions of insulin are its effects in regulating glucose homeostasis and energy balance $(3,4)$. It is increasingly evident that there are complex interactions among the various sites of insulin action. Here we demonstrate that normalization of hepatic insulin signaling has an impact on insulin action in mice lacking Insr in muscle and fat and displaying decreased insulin signaling in the hypothalamus. Surprisingly, the restoration of near normal Insr expression and signaling in the liver of Insr knockout mice is not sufficient to rescue hepatic insulin action in vivo. Since reversal of liver insulin resistance is a prominent goal of diabetic therapy, our results raise serious questions as to what are the more desirable tissue targets for therapeutic interventions designed to improve insulin signaling.

\section{Methods}

Mice. The mutant mice used for these studies have been described in a prior publication (16) and are referred to as L1. They were generated by intercrosses of mice bearing a transthyretin-driven human INSR cDNA with Insr heterozygous knockout mice. We thus obtained mice lacking endogenous Insr and expressing the mutant transgene in hepatocytes, pancreatic $\beta$ cells, and selective brain cells. As shown before, we detected expression in all parts of the brain examined, including the hypothalamus. Mice were maintained by brother-sister mating as an $\mathrm{F}_{2}$ cross. Their genetic makeup is complex, as it contains chromosomes derived from the $129 \mathrm{sv}, \mathrm{C} 57 \mathrm{BL} / 6 \mathrm{~J}$, and FVB genomes. We used WT littermates as controls, to provide as close a genetic match as reasonably possible. Mutant $(n=22)$ and WT mice $(n=21)$ were divided into 3 separate cohorts either receiving glucose tracer infusions under basal ( $\sim 5$-hour fast) conditions, undergoing insulin clamp studies, or receiving insulin injections for signaling experiments.

Body composition. Body composition was assessed using 2 independent methods. A whole-body magnetic resonance analyzer for mice (Echo Medical Systems) was used to perform a quantitative magnetic resonance analysis of fat-free mass and fat mass. In a separate cohort of mice, the percentage of fat mass was also determined using the low partition coefficient of tritium-labeled water $\left({ }^{3} \mathrm{H}_{2} \mathrm{O}\right)$. A known amount $(5 \mu \mathrm{Ci})$ of ${ }^{3} \mathrm{H}_{2} \mathrm{O}$ was injected into the i.p. cavity, and plasma samples were obtained at 60 -minute intervals over 3 hours. Steady state conditions for plasma ${ }^{3} \mathrm{H}_{2} \mathrm{O}$-specific activity were achieved within 60 minutes in all studies. The distribution of tracer in the aqueous compartment was used to calculate the contribution of the lipid stores to the total body weight. The whole-body distribution space of water was obtained by dividing the total amount of ${ }^{3} \mathrm{H}_{2} \mathrm{O}$ radioactivity injected (in $\mathrm{dpm}$ ) by the steady-state specific activity of plasma water (in $\mathrm{dpm} / \mathrm{ml}$ ). Plasma was assumed to be $93 \%$ water. Fat-free mass was calculated as the whole-body water distribution space divided by 0.73 and fat mass as the difference between body weight and fat-free mass.

Calorimetry. Animals undergoing indirect calorimetry were acclimated to the respiratory chambers for 1 day before the gas exchange measurements. Mice were individually housed in the calorimeter cages, and data on gas exchanges, activity, and food intake were collected for 2-3 days. Indirect calorimetry was performed with a computer-controlled open circuit calorimetry system (Oxymax; Columbus Instruments) composed of 4 respiratory chambers with an elevated plastic mesh floor. Each chamber is equipped with a water bottle, a food tray connected to a balance, and an activity monitor. Oxygen consumption and carbon dioxide production were measured for each mouse at 6-minute intervals. Outdoor air reference values were measured after every 10 consecutive $\mathrm{O}_{2}$ and $\mathrm{CO}_{2}$ measurements. Instrument settings were as follows: gas flow rate $=0.5 \mathrm{l} /$ minute; settle time $=240$ seconds; measure time $=60$ seconds. Gas sensors were calibrated daily with primary gas standards containing known concentrations of $\mathrm{O}_{2}, \mathrm{CO}_{2}$, and $\mathrm{N}_{2}$ (Tech Air). A mass flow meter was used to measure and control air flow. Oxygen was measured with an electrochemical oxygen sensor. $\mathrm{CO}_{2}$ was measured with a spectrophotometric sensor. RQ was calculated as the ratio between $\mathrm{CO}_{2}$ production (liters) over $\mathrm{O}_{2}$ consumption (liters). The RQ data were analyzed as an average of 24-hour resting RQ (Figure 2D) as well as PRCF (Figure 2E), as previously described by Liu et al. (19).

Euglycemic hyperinsulinemic clamp studies. We studied 2 groups of male mice. Group 1 included $12 \mathrm{~L} 1$ mice, and group 2 included 9 WT littermate controls. We bred and genotyped L1 mice as previously described (16). We performed experiments in 3-month-old male mice (Table 1). Following anesthesia, we placed an indwelling catheter into the right internal jugular vein; we carried out the studies 3 days after surgery, as previously described (37-40).

We performed euglycemic clamps in conscious, unrestrained, catheterized mice as previously described $(23,37,39,41)$. We removed food for 5-6 hours before the in vivo protocol. We infused a solution of glucose $(10 \%)$ at a variable rate as required to maintain euglycemia $(8 \mathrm{mM})$. Mice received a constant infusion of HPLC-purified $\left[3-{ }^{3} \mathrm{H}\right]$ glucose $(0.1 \mathrm{mCi} / \mathrm{min}$; Perkin Elmer) and insulin ( $3.6 \mathrm{mU} / \mathrm{kg}$ body weight $/ \mathrm{min})$. We collected plasma samples to determine glucose levels at times 10, 20, 30, 40, 50, 60, 70, 80, and 90 minutes after beginning the insulin and glucose infusions, and measured the specific activities of $\left[3-{ }^{3} \mathrm{H}\right]$ glucose and tritiated water at times 40, 50, 60, 70, 80, and 90 minutes after beginning the insulin and glucose infusions. We achieved steady-state conditions for both plasmaglucose concentration and specific activity within 40 minutes from the beginning of the insulin clamp. During the last 10 minutes of the clamp study, we infused a solution of $\left[\mathrm{U}-{ }^{14} \mathrm{C}\right]$ lactate in normal saline $(5 \mu \mathrm{Ci}$ as initial bolus, followed by $0.25 \mu \mathrm{Ci} / \mathrm{min}$ ). To assess insulin-stimulated glucose uptake in skeletal muscle, 2-deoxy-D-[1-14 C]glucose was administered as a bolus $(10 \mu \mathrm{Ci}) 45$ minutes prior to the end of the insulin clamp study. At the end of the in vivo studies, mice were anesthetized, abdomens were quickly opened, portal blood was collected, and liver and hindlimb mus- 
cles were freeze-clamped in situ with aluminum tongs that were cooled in liquid nitrogen. The time between the injection of anesthesia and freeze clamping of tissue samples was fewer than 60 seconds. Tissue samples were stored at $-80^{\circ} \mathrm{C}$ for further analysis.

For the in vivo assessment of downstream insulin signaling, additional groups of male L1 and WT mice were injected i.p. with a bolus of insulin (human recombinant; Sigma-Aldrich) following an overnight fast. After 15-30 minutes, animals were sacrificed and liver and hypothalamic nuclei were sampled.

Real-time RT-PCR analysis. We isolated mRNA using the Micro-Fast Track 2.0 kit (Invitrogen Corp.) and employed it to synthesize cDNA using a Gene Amp RNA PCR kit (Perkin Elmer). We carried out real-time PCR with SYBR in duplicate using a Light Cycler instrument (Roche Molecular Biochemicals). PCR amplification conditions were 2 minutes at $95^{\circ} \mathrm{C}$, followed by 35 cycles at $95^{\circ} \mathrm{C}$ for 1 minute each, $60^{\circ} \mathrm{C}$ for 1 minute, and $72^{\circ} \mathrm{C}$ for $1 \mathrm{~min}$ ute, with a final cycle at $72^{\circ} \mathrm{C}$ for 7 minutes. To normalize RNA content, we employed amplification of $\beta$-actin mRNA. We used the following primer set to amplify the various mRNAs: $\beta$-actin: $5^{\prime}$-CTAGAAGCACTTGCGGTGCAC-3' and 5'-GAAATCGTGCGTGACATCAAA-3'; G6pc: 5'-GCTTGGATTCTACCTGCTAC-3' and 5'-AAAGACTTCTTGTGTGTCTGTC-3'; Pepck: 5'-CCACAGCTGCTGCAGAACA-3' and 5'-AAAGACTTCTTGTGTGTCTGTC-3'; Igfbp1: 5'-AGATCGCCGACCTCAAGAAAT-3' and 5'-CTCCAGAGACCCAGGATTTT-3'.

Analytical procedures. We measured plasma glucose by the glucose oxidase method (Glucose Analyzer II; Beckman Coulter) and estimated rates of glycolysis as previously described (39). Because tritium on the C-3 position of glucose is lost to water during glycolysis, it is assumed that plasma tritium is present in either tritiated water or $\left[3-{ }^{3} \mathrm{H}\right]$ glucose. We measured radioactivity of $\left[3-{ }^{3} \mathrm{H}\right]$ glucose in plasma from supernatants of $\mathrm{Ba}(\mathrm{OH})_{2}$ and $\mathrm{ZnSO}_{4}$ precipitates after each was evaporated to dryness for the removal of tritiated water. The specific activity of tritiated water in plasma was determined from the total counts of the protein-free supernatant before and after evaporation to dryness (42).

Under steady-state conditions for plasma glucose concentration, the rate of glucose uptake equals the rate of glucose appearance $\left(R_{a}\right)$. We determined $\mathrm{R}_{\mathrm{a}}$ by dividing the infusion rate for $\left[3-{ }^{3} \mathrm{H}\right]$ glucose $(\mathrm{dpm})$ by the specific activity of plasma $\left[3-{ }^{3} \mathrm{H}\right]$ glucose $(\mathrm{dpm} / \mathrm{mg}$ glucose $)$ under steady-state conditions. We estimated the rate of glycogen synthesis from the difference between $\mathrm{R}_{\mathrm{a}}$ and the rate of glycolysis. We calculated the percentage of the hepatic glucose-6-phosphate pool directly derived from plasma glucose (direct pathway) as the ratio of liver $\left[3-{ }^{3} \mathrm{H}\right]$ uridine-diphospho-glucose-specific $\left(\left[3-{ }^{3} \mathrm{H}\right]\right.$ UDP-glucose-specific) activity to plasma $\left[3-{ }^{3} \mathrm{H}\right]$ glucose-specific activity $(43)$.

Protein extract preparation and Western blot analysis. We prepared detergent extracts from liver and hypothalamus of insulin- or saline-injected mice in buffer containing $20 \mathrm{mM}$ Tris ( $\mathrm{pH} 7.5$ ), 1\% NP40, $10 \mathrm{mM}$ magnesium chloride, $10 \mathrm{mM}$ EGTA, $1 \mathrm{mM}$ DTT, $2 \mathrm{mM}$ PMSF, and $1 \mathrm{mM}$ sodium orthovanadate. For microdissection of the brain, we cut 1-mmthick sagittal sections using a cooled mouse brain matrix. By identifying landmarks such as fornix, optic tracts, and mammilary nuclei, we identified and dissected ARC and PVN regions. ARC and PVN regions were homogenized in the buffer described above with a $21 \mathrm{G}$ syringe. We resolved equal amounts of protein $(0.2 \mathrm{mg}$ for liver, $0.15 \mathrm{mg}$ for hypothalamus, and $0.1 \mathrm{mg}$ for ARC and PVN nuclei) on 10\% SDS-PAGE and transferred them to nitrocellulose membrane (Protoran; Schleicher $\&$ Schuell). For determination of Insr concentrations, we probed the filters with anti-Insr $\beta$ subunit antibody (C-19; Santa Cruz Biotechnology Inc.) at a 1:1000 dilution. We detected bound antibody with horseradish peroxidase-coupled antibodies against rabbit IgG (Amersham Biosciences) at 1:6000 dilution using the ECL detection system (Amersham Biosciences). For determination of total and phosphorylated Akt concentrations, we used anti-phospho Akt antibody (9271; Cell Signaling Technology) at a 1:1000 dilution, followed by detection with anti-rabbit IgG antiserum and ECL. To normalize for protein content, we stripped the filters and reprobed them with anti-Akt antibody (9272; Cell Signaling Technology) at a 1:1000 dilution. For determination of tubulin concentrations, we used anti- $\beta$-tubulin antibody (Tu 27, Berkeley Antibody Company) at a 1:1000 dilution, followed by detection with anti-mouse IgG antiserum and ECL. We measured the intensity of the bands corresponding to Insr and Akt using scanning densitometry of the autoradiograms with NIH ImageJ software (version 1.29x; NIH). For the immunoblots displayed in Figure 1B, we immunoprecipitated equal amounts (3 $\mathrm{mg}$ protein) of liver extracts using anti-IRS1 antibody (06-248; Upstate) and immunoblotted the precipitants using anti-phosphotyrosine antibody (05-321; Upstate; 1:2000) (panel 1) or anti-PI3K p85 antibody (06-497; Upstate; $1: 1000)$. After stripping the antibodies from the filters, we repeated the immunoblot using anti-IRS1 antibody (06-248; Upstate; $1: 1000)$. We immunoblotted equal amounts (100 $\mu$ g protein) of total liver extracts using p85-antibody, phosphorylated Foxo1 antibody (9461; Cell Signaling Technology; 1:1000), or Foxo1 antibody (H128; Santa Cruz Biotechnology Inc.; 1:200).

All values are presented as the mean \pm SE. Unpaired nonparametric Student's $t$ test was used for statistical analysis. We selected a threshold for statistical significance of $P<0.05$. The study protocol was approved by the Institutional Animal Care and Use Committee of the Albert Einstein College of Medicine.

\section{Acknowledgments}

We thank Yuhua Wang, Bing Liu, Stanislaw Gaweda, and Clive Baveghems for expert technical assistance. This work was supported by NIH and American Diabetes Association grants to D. Accili, S. Obici, and L. Rossetti and by the Columbia University Diabetes and Endocrinology Research Center and the Albert Einstein College of Medicine Diabetes Research and Training Center. We thank members of the Accili and Rossetti laboratories for helpful discussion of the data.

Received for publication August 19, 2004, and accepted in revised form February 7, 2005.

Address correspondence to: Luciano Rossetti, Albert Einstein College of Medicine, 1300 Morris Park Avenue, Bronx, New York 10461, USA. Phone: (718) 430-4118 or (718) 430-4215; Fax: (718) 430-8557; E-mail: rossetti@aecom.yu.edu.
1. Saltiel, A.R., and Kahn, C.R. 2001. Insulin signalling and the regulation of glucose and lipid metabolism. Nature. 414:799-806.

2. Liu, Z., and Barrett, E.J. 2002. Human protein metabolism: its measurement and regulation. Am. J. Physiol. Endocrinol. Metab. 283:E1105-E1112.

3. Schwartz, M.W., Woods, S.C., Porte, D., Jr., Seeley, R.J., and Baskin, D.G. 2000. Central nervous system control of food intake. Nature. 404:661-671.
4. Obici, S., and Rossetti, L. 2003. Minireview: nutrient sensing and the regulation of insulin action and energy balance. Endocrinology. 144:5172-5178.

5. Ferrannini, E., et al. 1999. Insulin: new roles for an ancient hormone. Eur. J. Clin. Invest. 29:842-852.

6. Kitamura, T., Kahn, C.R., and Accili, D. 2003. Insulin receptor knockout mice. Annu. Rev. Physiol. 65:313-332.

7. Michael, M.D., et al. 2000. Loss of insulin signal- ing in hepatocytes leads to severe insulin resistance and progressive hepatic dysfunction. Mol. Cell. 6:87-97.

8. Kulkarni, R.N., et al. 1999. Tissue-specific knockout of the insulin receptor in pancreatic beta cells creates an insulin secretory defect similar to that in type 2 diabetes. Cell. 96:329-339.

9. Bruning, J.C., et al. 2000. Role of brain insulin receptor in control of body weight and reproduction. 
Science. 289:2122-2155.

10. Banerjee, R.R., et al. 2004. Regulation of fasted blood glucose by resistin. Science. 303:1195-1198.

11. Rangwala, S.M., et al. 2004. Abnormal glucose homeostasis due to chronic hyperresistinemia. Diabetes. 53:1937-1941.

12. Muse, E.D., et al. 2004. Role of resistin in dietinduced hepatic insulin resistance. J. Clin. Invest. 114:232-239. doi:10.1172/JCI200421270.

13. Accili, D. 2004. Lilly lecture 2003: the struggle for mastery in insulin action: from triumvirate to republic. Diabetes. 53:1633-1642.

14. Kido, Y., et al. 2000. Tissue-specific insulin resistance in mice with mutations in the insulin receptor, IRS-1, and IRS-2. J. Clin. Invest. 105:199-205.

15. Bruning, J.C., et al. 1997. Development of a novel polygenic model of NIDDM in mice heterozygous for IR and IRS-1 null alleles. Cell. 88:561-572.

16. Okamoto, H., et al. 2004. Transgenic rescue of insulin receptor-deficient mice. J. Clin. Invest. 114:214-223. doi:10.1172/JCI200421645.

17. Bluher, M., et al. 2002. Adipose tissue selective insulin receptor knockout protects against obesity and obesity-related glucose intolerance. Dev. Cell. 3:25-38.

18. Kim, J.K., et al. 2000. Redistribution of substrates to adipose tissue promotes obesity in mice with selective insulin resistance in muscle. J. Clin. Invest. 105:1791-1797.

19. Liu, X., et al. 2003. Paradoxical resistance to dietinduced obesity in UCP1-deficient mice. J. Clin. Invest. 111:399-407. doi:10.1172/JCI200315737.

20. Cherrington, A.D. 1999. Banting Lecture 1997. Control of glucose uptake and release by the liver in vivo. Diabetes. 48:1198-1214.

21. Sindelar, D.K., et al. 1998. Basal hepatic glucose production is regulated by the portal vein insulin concentration. Diabetes. 47:523-529.

22. Boden, G., Chen, X., Ruiz, J., White, J.V., and Rossetti, L. 1994. Mechanisms of fatty acid-induced inhibition of glucose uptake. J. Clin. Invest.
93:2438-2446

23. Lewis, G.F., Vranic, M., Harley, P., and Giacca, A 1997. Fatty acids mediate the acute extrahepatic effects of insulin on hepatic glucose production in humans. Diabetes. 46:1111-1119.

24. Rebrin, K., Steil, G.M., Mittelman, S.D., and Bergman, R.N. 1996. Causal linkage between insulin suppression of lipolysis and suppression of liver glucose output in dogs. J. Clin. Invest. 98:741-749.

25. Obici, S., Zhang, B.B., Karkanias, G., and Rossetti, L. 2002. Hypothalamic insulin signaling is required for inhibition of glucose production. Nat. Med. 8:1376-1382.

26. Hornbuckle, L.A., et al. 2001. Selective tonic inhibition of G-6-Pase catalytic subunit, but not G-6-P transporter, gene expression by insulin in vivo. Am. J. Physiol. Endocrinol. Metab. 281:E713-E725.

27. Fisher, S.J., and Kahn, C.R. 2003. Insulin signaling is required for insulin's direct and indirect action on hepatic glucose production. J. Clin. Invest. 111:463-468. doi:10.1172/JCI200316426.

28. Gabbay, R.A., et al. 1996. Insulin regulation of phosphoenolpyruvate carboxykinase gene expression does not require activation of the Ras/mitogen-activated protein kinase signaling pathway. J. Biol. Chem. 271:1890-1897.

29. Wolkow, C.A., Kimura, K.D., Lee, M.S., and Ruvkun, G. 2000. Regulation of C. elegans life-span by insulinlike signaling in the nervous system. Science. 290: $147-150$

30. Apfeld, J., and Kenyon, C. 1998. Cell nonautonomy of C. elegans daf- 2 function in the regulation of diapause and life span. Cell. 95:199-210.

31. Obici, S., Feng, Z., Karkanias, G., Baskin, D.G., and Rossetti, L. 2002. Decreasing hypothalamic insulin receptors causes hyperphagia and insulin resistance in rats. Nat. Neurosci. 5:566-572.

32. Lauro, D., et al. 1998. Impaired glucose tolerance in mice with a targeted impairment of insulin action in muscle and adipose tissue. Nat. Genet. 20:294-298.

33. Bruning, J.C., et al. 1998. A muscle-specific insulin receptor knockout exhibits features of the metabolic syndrome of NIDDM without altering glucose tolerance. Mol. Cell. 2:559-569.

34. Fernandez, A., et al. 2001. Functional inactivation of the IGF-I and insulin receptors in skeletal muscle causes type 2 diabetes. Genes. Dev. 15:1926-1934.

35. Joshi, R.L., et al. 1996. Targeted disruption of the insulin receptor gene in the mouse results in neonatal lethality. $E M B O J .15: 1542-1547$.

36. Accili, D., et al. 1996. Early neonatal death in mice homozygous for a null allele of the insulin receptor gene. Nat. Genet. 12:106-109.

37. Rossetti, L., et al. 1997. Abnormal regulation of HGP by hyperglycemia in mice with a disrupted glucokinase allele. Am. J. Physiol. 273:E743-E750.

38. Rossetti, L., et al. 1996. Hepatic overexpression of insulin-like growth factor-II in adulthood increases basal and insulin-stimulated glucose disposal in conscious mice. J. Biol. Chem. 271:203-208.

39. Massillon, D., et al. 1995. Quantitation of hepatic glucose fluxes and pathways of hepatic glycogen synthesis in conscious mice. Am. J. Physiol. 269:e1037-e1043

40. Bali, D., et al. 1995. Animal model for maturityonset diabetes of the young generated by disruption of the mouse glucokinase gene. J. Biol. Chem. 270:21464-21467.

41. Combs, T.P., Berg, A.H., Obici, S., Scherer, P.E., and Rossetti, L. 2001. Endogenous glucose production is inhibited by the adipose-derived protein Acrp30. J. Clin. Invest. 108:1875-1881. doi:10.1172/ JCI200114120.

42. Rossetti, L., and Giaccari, A. 1990. Relative contribution of glycogen synthesis and glycolysis to insulin-mediated glucose uptake. A dose-response euglycemic clamp study in normal and diabetic rats. J. Clin. Invest. 85:1785-1792.

43. Barzilai, N., and Rossetti, L. 1993. Role of glucokinase and glucose-6-phosphatase in the acute and chronic regulation of hepatic glucose fluxes by insulin. J. Biol. Chem. 268:25019-25025. 